open 2 ACcess

\title{
Oral Manifestations of Coronavirus Disease-19: A Mini-review
}

\author{
Hamed Mortazavi ${ }^{1}$, Kosar Rezaeifar $^{2 *}$, Navid Nasrabadi ${ }^{3}$ \\ ${ }^{1}$ Professor, Department of Oral Medicine, School of Dentistry, Shahid Beheshti University of Medical Sciences, Tehran, Iran; \\ ${ }^{2}$ Assistant Professor, Department of Oral Medicine, School of Dentistry, Ahvaz Jundishapur University of Medical Sciences, \\ Ahvaz, Iran; ${ }^{3}$ Post Graduate Student, Department of Endodontics, School of Dentistry, Shahid Beheshti University of Medical \\ Sciences, Tehran, Iran
}

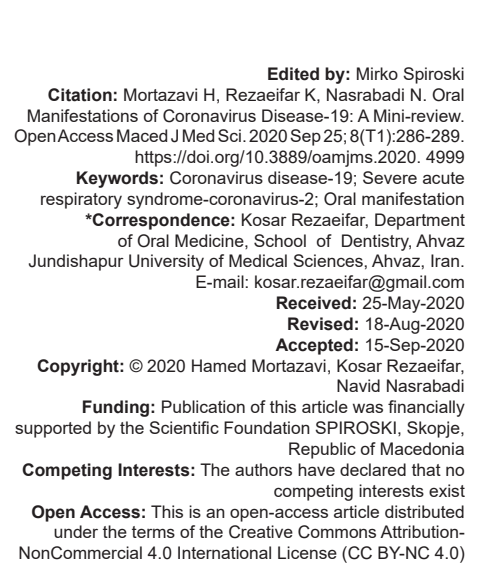

\section{Abstract}

BACKGROUND: Recently, outbreak of novel coronavirus (CoV) (severe acute respiratory syndrome-CoV-2 [SARSCoV-2]) has been emerged as a serious public health concern. On February 11, 2020, the WHO announced an official name for this disease, CoV disease-(COVID)-19. The virus can cause systemic complications such as lung involvement, skin, and oral complications.

AIM: The aim of this study was to review of the oral manifestations of COVID-19.

METHODS: In this narrative review study, we searched all articles between 2010 and 2020 in PubMed, Scopus Science Direct related to COVID-19, and its oral manifestations, using the following terms: "Coronavirus," "COVID19," and "SARS-CoV-2" in combination with "Stomatognathic diseases," "Oral manifestation," and "Mouth diseases." RESULTS: The most common oral manifestations in people with COVID-19 that we get after searching are: salivary gland disease, xerostomia, taste and smell alterations, and oral mucosal lesions.

CONCLUSIONS: Since almost all of the oral findings appear at the asymptomatic phase of disease, identification of these symptoms can help to timely diagnosis of the main disease.

\section{Introduction}

The novel coronavirus (CoV) disease 2019 (COVID) (severe acute respiratory syndrome-CoV-2 [SARS-CoV-2] or COVID-19) presents as a serious public health concern and urgent threat to global health [1].

In December 2019, COVID-19 was detected in Wuhan, China. It has a very high transmission capacity and is known as SARS-CoV-2 [2].

COVID-19 is highly contagious and it has the ability to get transmitted even during asymptomatic phase. The infectivity of COVID-19 is greater than that of influenza; it is necessary to identify infected people as soon as possible, even during the asymptomatic period [3].

The current CoV outbreak is the third epidemic viral infection in the $21^{\text {st }}$ century [3]. The lungs are the primary site of infection for COVID-19, with patients presenting symptoms ranging from mild flu-like symptoms to fulminant pneumonia and potentially lethal respiratory distress [1].

All age groups are susceptible to the virus and some people are more susceptible to the virus such as older people ( $\geq$ aged 65 ), patients with immunodeficiency or liver and kidney failure, healthcare staff caring for
COVID-19 patients, and other individuals who closely are in contact with these patients in clinical settings [3].

Although the complete clinical representation regarding COVID-19 is not fully understood, here are some common clinical manifestations. This virus can cause disease ranging from mild to severe, the clinical characteristics of mild COVID-19 include symptoms common to other viral infections (i.e., fever, cough, dyspnea, myalgia, fatigue, and diarrhea) [3], [4].

In severe cases, COVID-19 may present as acute respiratory distress syndrome, with or without both distributive and cardiogenic shock [4].

The oral manifestations of COVID-19 are varied and there is insufficient evidence to establish an efficient and safe pharmacological agent against COVID-19 yet, and the potential ones are related to several adverse reactions, including oral lesions [1].

The mouth is one of the sites that can be infected by the virus and show manifestations of the disease. Therefore, dentists can be one of the first people to diagnose the disease based on oral manifestations, even in the asymptomatic stages, and prevent the spread of the disease. Our purpose in this study is to identify and summarize oral manifestations related to COVID-19. 


\section{Search Strategy}

This article is a narrative review study and according to its nature as "narrative," we chose the most relevant contributions to oral manifestations of COVID-19.

The search was conducted using six MeSH keywords including, "Coronavirus," "COVID-19," "SARSCoV-2," "Stomatognathic diseases," "Oral manifestation," and "Mouth disease" in PubMed, Scopus, and Science Direct databases among articles between 2010 and 2020. Of 80 related articles, 42 were excluded due to lack of full text, being written in a language other than English or containing repetitive material and 38 were closely relevant to the title. Finding 24 well documented English articles were chosen, including clinical trial (5 articles), review (6 articles), cohort (2 articles), case report ( 3 articles), cross-sectional studies (1 article), and letter to editor ( 7 articles) were reviewed.

\section{Results}

Finally, we found four different types of oral manifestations of COVID-19 which are included as salivary gland disease, xerostomia, taste/smell alterations, and oral mucosal lesions (Table 1).

\section{Discussion}

There have been limited studies about oral manifestations of COVID-19, review of literature showed that most researchers paying more attention to systemic manifestations, and therefore we focused on oral-related symptoms, which may provide new clinical information for COVID-19.

In the following, we will refer to oral finding and its relation to clinical findings. Some of the side effects that we get after searching are:

\section{Salivary Gland Disease}

Salivary gland can be involved in patients with CoV infection [5]. Angiotensin-converting enzyme II (ACE2) has been reported as an important receptor for COVID-19 [6], [7]. Xu et al. demonstrated that the expression of ACE2 in minor salivary glands was higher than in lungs, which suggests salivary glands could be a potential target for COVID-19 [8]. In accordance to these findings, Chen et al. evaluated the expression of ACE2 receptor of 2019-nCoV in salivary gland epithelial cells and demonstrated the possibility of 2019-nCoV infection of the salivary glands. They also mentioned the reason that the positive saliva detection rate was as high as $75 \%$ in critically ill patients may be related to virus invasion caused by high viral loads or destroyed salivary glands at the late stage of the disease [9]. The same results have been also reported by To et al. and Kotfis and Skonieczna-Żydecka [10], [11]. It is important to know, COVID-19 was only detected in saliva, with no evidence for its presence in the nasopharynx [12].

\section{Xerostomia}

In a study by Chen et al., among the oralrelated symptoms in COVID-19 patients, amblygeustia $(47.2 \%)$ overall, male $(36.5 \%)$, female $(57.1 \%)$ and xerostomia $(46.3 \%)$ overall, male $(46.2 \%)$, female $(46.4 \%)$ had the most frequencies of occurrence. In addition, $11.1 \%$ male $(13.5 \%)$ and female $(8.90 \%)$ of the patients exhibited dryness and inflammation of the mouth. One female patient $(0.9 \%)$ had enlargement of lymph nodes in the submandibular regions [8]. In a study by Yifan et al., the ten most frequent symptoms in the studied patients were chest discomfort $(31.4 \%)$, dyspnea $(30.7 \%)$, nausea $(21.4 \%)$, headache $(19.3 \%)$, dizziness $(17.9 \%)$, xerostomia $(15.7 \%)$, fatigue $(15 \%)$, sleepiness $(9.3 \%)$, sweating $(8.6 \%)$, and waist pain $(7.1 \%)$ [13]. Besides viral invasion to the salivary glands and its negative effect on peripheral and central nervous systems, dry mouth may also be due to the patient's

Table 1: Oral manifestations of COVID-19 in some published articles

\begin{tabular}{|c|c|c|c|c|c|}
\hline \multirow[t]{2}{*}{ Author } & \multirow[t]{2}{*}{ Year of publication } & \multicolumn{4}{|l|}{ Oral manifestations } \\
\hline & & Salivary gland involvement & Xerostomia & Taste and Smell alterations & Oral mucosal lesion \\
\hline Xu et al. [7] & 2020 & * & & & \\
\hline Chen et al. [9] & 2020 & * & * & * & \\
\hline To et al. [10] & 2020 & * & & & \\
\hline Kotfis and Skonieczna-Żydecka [11] & 2020 & * & & & \\
\hline Keyhan et al. [12] & 2020 & & * & & \\
\hline Yifan et al. [13] & 2020 & & * & & \\
\hline Amorim Dos Santos et al. [1] & 2020 & & * & & * \\
\hline Odeh et al. [14] & 2020 & & & * & \\
\hline Giacomelli et al. [15] & 2020 & & & * & \\
\hline Lechien et al. [16] & 2020 & & & * & \\
\hline Vaira et al. [17] & 2020 & & & * & \\
\hline Hopkins et al. [18] & 2020 & & & * & \\
\hline Chaux-Bodard et al. [20] & 2020 & & & & * \\
\hline Martín Carreras-Presas et al. [22] & 2020 & & & & * \\
\hline Dziedzic and Wojtyczka [23] & 2020 & & & & * \\
\hline Vieira [24] & & & & & * \\
\hline
\end{tabular}


change in psychological status, poor oral hygiene, or adverse drug effects [9], [12]. According to Amorim Dos Santos et al., the occurrence of xerostomia in COVID19 patients linked to decreased salivary flow [1].

\section{Taste and Smell Alterations}

Taste and smell abnormalities have been recognized as symptoms of 2019-nCoV [14]. According to Giacomelli et al., about 34\% of COVID-19 patients had at least one taste or olfactory disorders and $18.6 \%$ had both of them [15]. More than $20 \%$ of patients presented the symptoms before the hospital admission, whereas $13.5 \%$ experienced the symptoms during the hospitalization. Taste alterations were more common (91\%) before hospitalization, whereas after hospitalization, taste and olfactory alteration appeared with an equal percentage. Women reported olfactory and taste disorders more frequently than men (52.6\% vs. $25 \%)$. Moreover, patients with at least 1 olfactory and taste disorder were younger than those without [15]. In a multicenter European study by Lechien et al., $79.7 \%$ of patients with mildto-moderate forms of the coronavirus disease were hyposmic or anosmic [16]. In addition, according to Vaira et al., in $15.3 \%$ of patients, temporary taste and smell abnormalities were only manifestations of COVID-19 and there is a statistically significant relationship between the duration of the chemosensitive disorder and the severity of the disease [17]. For example, patients who had a history of taste and smell alteration for more than 10 days, the risk of developing a severe pulmonary clinical picture was 2.4 times greater [17]. In another study by Hopkins et al., $86.4 \%$ of patients reported complete anosmia and $11.5 \%$ reported a very severe loss of smell at the time of the first survey. At follow-up 1 week later, lower severity, unchanged severity, and higher severity scores have been reported in $80.1 \%, 17.6 \%$, and $1.9 \%$ of cases, respectively [18]. These abnormalities could be explained by the interaction between virus and ACE2 receptors. In fact, the expression of ACE2 was found to be higher in the tongue, where the taste buds are most frequent than other sites such as gingival or buccal mucosa [9]. On the other hand, Keyhan et al. described that the presence of dysosmia and dysgeusia can be related to olfactory nerve and trigeminal nerve damage caused by virus invasion or excessive exposure to chemicals and disinfectant agents that are used by people due to the viral epidemic [12]

\section{Oral Mucosal Lesions}

Cutaneous lesions related to 2019-nCoV infection have been described by dermatologists [19], but to our knowledge, there is limited information about oral mucosal lesions with a proven COVID-19 infection. In this regard, Chaux-Bodard et al. reported a COVID-19 related oral ulcer in a 45-year-old female. History of the lesion revealed painful inflammation on the dorsal side of the tongue, followed by $24 \mathrm{~h}$ of the erythematous macula, which changed into an asymptomatic and irregular ulcer. Three days after the occurrence of the oral lesion, asymptomatic erythematous area was appeared on the big toe; however, general symptoms were mild asthenia. The oral ulcer completely healed after 10 days without a scar. The tongue ulcer occurred after a short time of erythematous macular lesion, which could be explained by vasculitis [20]. COVID is in association with variable inflammatory reactions that can lead to vasculitis [21]. Thus, an irregular, acute, and solitary oral ulcer could be an inaugural symptom of 2019-nCoV infection which needs to be proven in large cohorts of patients [20]. In another case report by Martín Carreras-Presas et al., they showed oral vesiculobullous lesions associated with SARS-CoV-2 infection in three cases. The first case was a 56-year-old healthy male with the lesions resembled a herpetic recurrent stomatitis on the hard palate. The second case was a diabetic 58-yearold male with multiple small ulcers on his palate with unilateral affection and the last case was a 65-year-old female with blisters in her internal lip mucosa as well as desquamative gingivitis. It is important to know that all reported cases had pain, oral ulcers, and blisters before seeking medical advice [22].

On the other hand, stomatitis, oral ulcers, and dry mouth may be related to the side effects of antiviral drugs such as interferon-alpha and beta in $<2 \%$ of cases [23].

Amorim Dos Santos et al., in a case report study, showed that COVID-19 could potentially contribute to adverse outcomes concerning oral health, likely leading to various opportunistic fungal infections, recurrent oral herpes simplex virus-1 infection, and gingivitis as a result of the impaired immune system and/or due to treatments for COVID-19 [1]. Vieira showed that in severe cases of COVID-19, prior underlying untreated moderate or severe periodontitis may worsen COVID-19. Hence, periodontal therapy in patient with initial symptoms of COVID-19 may reduce the risk of the condition to become severe [24].

\section{Conclusion}

Salivary gland disease, xerostomia, taste and smell alternation and oral mucosal lesions are the most common oral changes reported about COVID19. Since almost all of the oral findings appear at asymptomatic phase of disease, identification of these 
symptoms can help to timely diagnosis of the main disease. Furthermore, it is unclear that these oral manifestations are coexisting or the result of a cause and effect that the virus reality has the ability to cause these manifestations. Due to the fact that the virus has not been around for a long time and many of the longterm effects of the virus have not been known yet, more extensive studies are needed.

\section{References}

1. Amorim Dos Santos J, Normando AG, Carvalho Da Silva RL, De Paula RM, Cembranel AC, Santos-Silva AR, et al. Oral mucosal lesions in a COVID-19 patient: New signs or secondary manifestations? Int J Infect Dis. 2020;97:326-8. https://doi. org/10.1016/j.ijid.2020.06.012

PMid:32526392

2. Razavi A, Davoodi L, Shojaei L, Jafarpour H. COVID-19 in children: A narrative review. Open Access Maced J Med Sci. 2020;8(T1):23-31. https://doi.org/10.3889/oamjms.2020.4714

3. Rezabakhsh A, Ala A, Khodaei SH. Novel coronavirus (COVID-19): A new emerging pandemic threat. J Res Clin Med. 2020;8(1):5. https://doi.org/10.34172/jrcm.2020.005

4. Driggin E, Madhavan MV, Bikdeli B, Chuich T, Laracy J, BiondiZoccai G, et al. Cardiovascular considerations for patients, health care workers, and health systems during the COVID-19 pandemic. J Am Coll Cardiol. 2020;75(18):2352-71. https://doi. org/10.1016/j.jacc.2020.03.031

PMid:32201335

5. Liu L, Wei O, Alvarez X, Wang H, Du Y, Zhu H, et al. Epithelial cells lining salivary gland ducts are early target cells of severe acute respiratory syndrome coronavirus infection in the upper respiratory tracts of rhesus macaques. J Virol. 2011;85(8):4025-30. https://doi.org/10.1128/jvi.02292-10 PMid:21289121

6. Xu H, Zhong L, Deng J, Peng J, Dan H, Zeng X, et al. High expression of ACE2 receptor of 2019-nCoV on the epithelial cells of oral mucosa. Int J Oral Sci. 2020;12(1):8. https://doi. org/10.1038/s41368-020-0074-X

7. Xu X, Chen P, Wang J, Feng J, Zhou H, Li X, et al. Evolution of the novel coronavirus from the ongoing Wuhan outbreak and modeling of its spike protein for risk of human transmission. Sci China Life Sci. 2020;63(3):457-60. https://doi.org/10.1007/ s11427-020-1637-5 PMid:32009228

8. Xu J, Li Y, Gan F, Du Y, Yao Y. Salivary glands: Potential reservoirs for COVID-19 asymptomatic infection. J Dent Res. 2020;99(8):989. https://doi.org/10.1177/0022034520918518 PMid:32271653

9. This Preprint Research Paper Has Not Been Peer Reviewed. Electronic Copy. Available from: https://www.ssrn.com/ abstract $=3557140$

10. To KK, Tsang OT, Yip CC, Chan KH, Wu TC, Chan JM, et al. Consistent detection of 2019 novel coronavirus in saliva. Clin Infect Dis. 2020;71(15):841-3. PMid:32047895

11. Kotfis K, Skonieczna-Żydecka K. COVID-19: gastrointestinal symptoms and potential sources of SARS-CoV-2 transmission. Anaesthesiol Intensive Ther. 2020;52(2):171-2. https://doi. org/10.5114/ait.2020.93867

PMid:32200613

12. Keyhan SO, Fallahi HR, Cheshmi B. Dysosmia and dysgeusia due to the 2019 novel coronavirus; a hypothesis that needs further investigation. Maxillofac Plast Reconstr Surg. 2020;42(1):9. https://doi.org/10.1186/s40902-020-00254-7 PMid:32289035

13. Yifan T, Ying L, Chunhong G, Jing S, Rong W, Zhenyu L, et al. symptom cluster of ICU nurses treating COVID-19 pneumonia patients in Wuhan, China. J Pain Symptom Manage. 2020;60(1):e43-53. https://doi.org/10.1016/j. jpainsymman.2020.03.039 PMid:32276095

14. Odeh ND, Babkair H, Abu-Hammad SH, Borzangy S, AbuHammad A, Abu-Hammad O, et al. COVID-19: Present and future challenges for dental practice. Int J Environ Res Public Health. 2020;17(9):3151. https://doi.org/10.3390/ijerph17093151 PMid:32366034

15. Giacomelli A, Pezzati L, Conti F, Bernacchia D, Siano M, Oreni L, et al. Self-reported olfactory and taste disorders in patients with severe acute respiratory coronavirus 2 infection: A cross-sectional study. Clin Infect Dis. 2020;71(15):889-90. https://doi.org/10.1093/cid/ciaa330 PMid:32215618

16. Lechien JR, Chiesa-Estomba CM, De Siati DR, Horoi M, Le Bon SD, Rodriguez A, et al. Olfactory and gustatory dysfunctions as a clinical presentation of mild-to-moderate forms of the coronavirus disease (COVID-19): A multicenter European study. Eur Arch Otorhinolaryngol. 2020;277(8):2251-61. https://doi. org/10.1007/s00405-020-06024-5

PMid:32253535

17. Vaira LA, Salzano G, De Riu G. The importance of olfactory and gustatory disorders as early symptoms of coronavirus disease (COVID-19). Br J Oral Maxillofac Surg. 2020;58(5):615-6. shttps://doi.org/10.1016/j.bjoms.2020.04.024 PMid:32362452

18. Hopkins C, Surda P, Whitehead E, Kumar BN. Early recovery following new onset anosmia during the COVID-19 pandemic-an observational cohort study. J Otolaryngol Head Neck Surg. 2020;49(1):26. https://doi.org/10.1186/s40463-020-00423-8

19. Recalcati S. Cutaneous manifestations in COVID-19: A first perspective. J Eur Acad Dermatol Venereol. 2020;43(5):e212-3. https://doi.org/10.1111/jdv.16387 PMid:32215952

20. Chaux-Bodard AG, Deneuve S, Desoutter A. Oral manifestation of Covid-19 as an inaugural symptom? J Oral Med Oral Surg. 2020;26(2):18. https://doi.org/10.1051/mbcb/2020011

21. Madjid M, Safavi-Naeini P, Solomon SD, Vardeny O. Potentia effects of coronaviruses on the cardiovascular system: A review. JAMA Cardiol. 2020;5(7):831-840. https://doi.org/10.1001/ jamacardio.2020.1286 PMid:32219363

22. Martín Carreras-Presas C, Amaro Sánchez J, LópezSánchez AF, Jané-Salas E, Somacarrera Pérez ML. Oral vesiculobullous lesions associated with SARS-CoV-2 infection. Oral Dis. 2020;???:???. https://doi.org/10.1111/odi.13382 PMid:32369674

23. Dziedzic, A, Wojtyczka, R. The impact of coronavirus infectious disease 19 (COVID-19) on oral health. Oral Dis. 2020;2020:1-4. https://doi.org/10.1111/odi.13359 PMid:32304276

24. Vieira AR. Oral manifestations in coronavirus disease 2019 (COVID-19). Oral Dis. 2020. https://doi.org/10.1111/odi.13463 